relationships in adolescents with obesity and FDC. Self-respect prevails in all adolescents. They can assess their strengths and weaknesses, they can agree they may be wrong, which does not let them accept that something is impossible to change, and quickly react and correct what is possible. State and trait anxiety is more pronounced in adolescents with obesity and FDC, and depressive symptoms are diagnosed in adolescents with IBS.

\section{P519 PSYCHOLOGICAL INTERVENTIONS AND MOTIVATION FOR WEIGHT LOSS IN GIRLS WITH ANDROID OBESITY}

Lyubov Rychkova, Ekaterina Sheneman, Tatyana Bairova, Vladimir Polyakov, Aryuna Kosovtseva*. Scientific Centre for Family Health and Human Reproduction Problems, Irkutsk, Russian Federation

\subsection{6/archdischild-2019-epa.854}

Background Android obesity in childhood is the most unfavorable for the lipid and carbohydrate metabolism disorders, formation of high blood pressure and diabetes. Adolescents with obesity have a low level of motivation to the weight loss. It reduces the effectiveness of obesity treatment. The aim of our study was to determine the changes in motivation and selfattitude after psychological counseling (including motivational interviewing) of girls with android exogenous constitutional obesity.

Methods The study included 43 girls with android exogenous constitutional obesity aged 13-17 years (age 15.5 \pm 1.0 ; SDS BMI 2.8 \pm 0.7; waist circumference 97.3 \pm 1.7). Group 1 consisted of girls who were treated for the first time according to this disease $(\mathrm{N}=23)$. Group 2 consisted of girls who were treated earlier but without positive effect $(\mathrm{N}=20)$. Primary and final diagnostics were carried out using methods of 'Diagnostics of the motivational sphere of the adolescent's personality' (J. Newten) and «Methods of self-attitude research» (S. R. Panteleev). Psychological counseling (including motivational interviewing) was conducted in the intermediate stage of this research to achieve changes in motives for treatment.

Results At the beginning of the study in girls of both groups the most pronounced motivation was the motivation of achievement, but without significant difference between studied groups. According to the "Methods of self-attitude research" the scale of self-accusing is significantly more pronounced in group $2(\mathrm{t}=2.76 ; \mathrm{p}<0.05)$. Diffidence, incredulity and restraint indicate that girls were feeling guilt for past failed attemptings of weight loss. After psychological interventions, we revealed a significant increase of motives of affiliations, support and self-development, without significant differences between the studied groups. All these indicators are focused on the process of treatment. Moreover, we found the stabilization of self-esteem, significant decrease in selfaccusing $(\mathrm{t}=2.88, \mathrm{p}<0.01)$ and an increase in self-acceptance $(t=2.74 ; \mathrm{p}<0.01)$.

Conclusion Psychological interventions are an important component of obesity treatment, they increase motivation for proper weight loss. Motivational interviewing and psychological correction are recommended at the initial stages of obesity treatment, especially in adolescents with android exogenousconstitutional obesity and previous unsuccessful treatment. Such an interdisciplinary approach will improve and retain the commitment to treatment.

\section{P520 \\ GROWTH PATTERNS IN A PAEDIATRIC OUTPATIENT CLINIC AT SLIGO UNIVERSITY HOSPITAL AND ITS ASSOCIATION WITH CHILD FOOD PREFERENCE AND PARENTAL PERCEPTION OF CHILD WEIGHT STATUS}

${ }^{1}$ Christine Houlihan*, ${ }^{2}$ Louise Rattigan, ${ }^{2}$ Dara Gallagher, ${ }^{2}$ Hilary Greaney, 'Laura Keaver. 'Institute of Technology Sligo, Sligo, Ireland; ${ }^{2}$ Sligo University Hospital, Sligo, Ireland

10.1136/archdischild-2019-epa.855

Background Limited research exists on the prevalence of childhood overweight and obesity at a regional level in Ireland. Child food preference and recognition of abnormal development are important in managing weight in children.

Aim Determine the prevalence of overweight and obesity amongst children 6 -15 year attending paediatric outpatient clinics at Sligo University Hospital (SUH). Determine the association between child food preference and weight. Identify if misclassification by parents of their own weight is associated with misclassification of the child's.

Method 52 parent child pairs were recruited over 4 weeks in a cross-sectional study at SUH. Weight and heights were measured in participants. Parents completed a survey that contained questions on weight status and interest in healthy lifestyle information. A validated 62-item food preference questionnaire was completed by children and adolescents. Statistical analysis was performed using SPSS $\mathrm{v} 24$. Significance was set at $\mathrm{p}<0.05$.

Results One quarter of children and adolescents were overweight or obese. A majority of the $25 \%$ of children with excess weight were obese. Obesity was more prevalent amongst girls and children above the age of nine. None of the children followed a vegetarian, vegan or pescatarian diet. A small number of children reported allergies (15.3\%). Food preference did not differ significantly between the different food groups. A slight trend was observed in children having an increased preference for fruits, snacks and starches, however there was no significant association between child food preference and weight. No parent recognised their child was overweight or obese. Parents misclassification of their own weight was not significantly associated with misclassification of their child's weight.

Discussion/Conclusion Obesity is becoming more of an issue in Irish children. The prevalence of overweight and obesity in this cohort reflect that of national figures. The influence of child and adolescent food preference on weight appears nonsignificant, this might suggest that it is portion size that plays a more significant role in weight status at this age than food group. Parents struggle to recognise overweight and obesity in children and adolescent and at present this represents a barrier to addressing abnormal growth.

\section{P521 LOW PHYSICAL ACTIVITY LEVELS AND HIGH SCREEN TIMES ARE ASSOCIATED WITH INCREASED WEIGHT AND ADVERSE BODY COMPOSITION AT 5 YEARS OF AGE: FINDINGS FROM THE ROLO KIDS STUDY}

Aisling A Geraghty, Eileen C O'Brien*, Mary K Horan, Jean Donnelly, Elizabeth Larkin, Fionnuala M McAuliffe. UCD Perinatal Research Centre, School of Medicine, University College Dublin, National Maternity Hospital, Dublin 2, Ireland

10.1136/archdischild-2019-epa.856

Background Childhood obesity rates have reached epidemic proportions world-wide, identifying modifiable factors to 